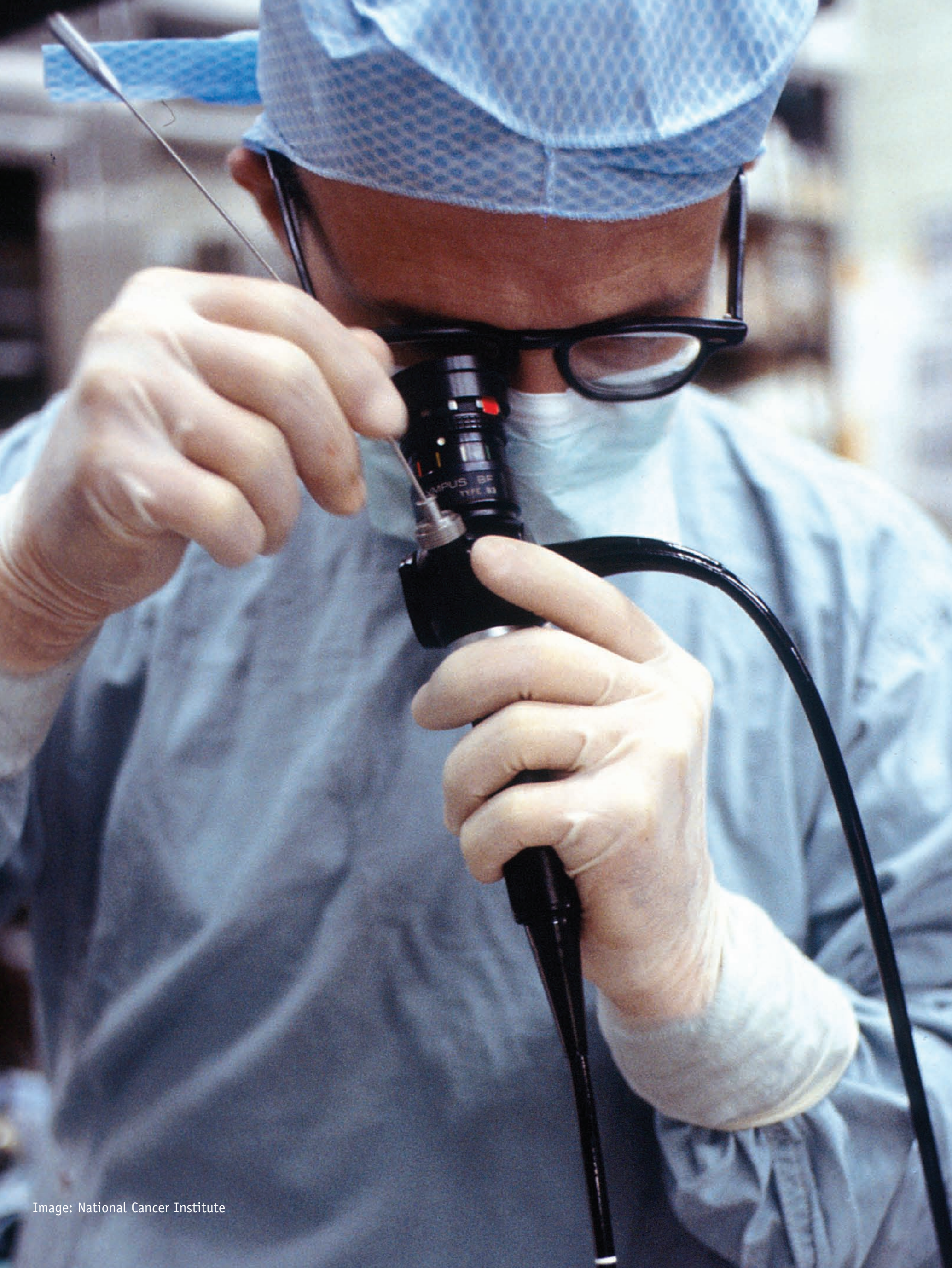




\section{Bronchoscopic techniques in diagnosis and staging of lung cancer}

\section{Summary}

Technologic advances in bronchoscopy continue to improve our ability to perform minimally invasive, accurate evaluations of the tracheobronchial tree and to perform an ever-increasing array of diagnostic, therapeutic, and palliative interventions. The role of both "old" and "new" diagnostic bronchoscopy will continue to evolve as further improvements are made in bronchoscopes, accessory equipment, and imaging technologies. The major challenge in the adoption of the many new bronchoscopic techniques into routine clinical practice is the need for well-designed studies to delineate the appropriate use of these interventions and to better define their limitations.

\section{Introduction}

The first bronchoscopy was performed in 1887 by Gustav Killian of Freiburg, Germany [1].

During the early years of the development of bronchoscopy, the indications for the procedure were primarily therapeutic: removal of foreign bodies and dilation of strictures from tuberculosis and diphtheria. In the early part of the 20th century, Chevalier Jackson, the father of American Broncho-Esophagology Association, further advanced bronchoscopic techniques and designed modern rigid bronchoscopies [2]. Again, the primary indication was often therapeutic.

Fibreoptic bronchoscopy (FOB) was developed in the late 1960s by S. Ikeda [3] and has become the mainstay investigation in the evaluation of patients suspected of lung cancer. It is employed mainly as a diagnostic tool providing tissue to determine the histological type of tumour. Bronchoscopy also has a role in disease staging and an extended role in delivering therapeutic modalities. FOB is convenient to perform, safe and well tolerated by the patient.

The requirement of minimal sedation makes it acceptable as an outpatient procedure, thus it has almost completely replaced rigid bronchoscopy in the initial assessment. The development of video bronchoscopes has the added advantage of facilitating teaching and rendering the procedure more interesting for other observers in the bronchoscopy suite.

The flexibility of the bronchoscope allows the operator to inspect the majority of fourthorder and often up to sixth-order bronchi. In addition, the operator may directly assess mucosal details, such as colour and vascularity. Relative contraindications to the procedure are few and include: hypoxaemia refractory to supplemental oxygen $\left(\mathrm{O}_{2}\right)$, intractable bleeding diathesis, severe pulmonary hypertension, cardiovascular instability and acute hypercapnia [4].

FOB is safe with a complication rate of $0.12 \%$ and a mortality rate of $0.04 \%$ [5]. The dangers of haemorrhage and pneumothorax relate to the biopsy procedure used and will be discussed later. In all patients, the bronchoscope causes a temporary increase in airflow obstruction, which may result in hypercapnia [6]. Inappropriate sedation with benzodiazepines or opiates will increase the likelihood of respiratory complications and high-risk patients should be identified by prior measurement of arterial blood gases [5-7].

\section{F.J.F. Herth}

\section{Correspondence}

F.J.F. Herth

Department Pneumology and Critical Care Medicine

Thoraxklinik at the University of Heidelberg

Amalienstraße 5

D-69126 Heidelberg

Germany

Felix.Herth@

thoraxklinik-heidelberg.de

Competing interests None declared. 
Supplemental $\mathrm{O}_{2}$ should be provided and patients should be monitored throughout with pulse oximetry. Cardiac monitoring should be used for those patients with a history of ischaemic heart disease and resuscitation equipment immediately available.

Although FOB has largely replaced rigid bronchoscopy in the initial assessment of the patient, the rigid scope has advantages in certain situations [8]. As mentioned, it may provide more accurate information regarding the endobronchial location of a tumour prior to resection.

Additionally, manipulation of the scope allows assessment of the mobility of the proximal airways providing an indirect evaluation of mediastinal nodal involvement. Airway obstruction is less and thus the rigid scope may be preferable in exploring patients with tracheal narrowing in whom the flexible scope may produce critical airway narrowing. It provides superior suction, facilitating the assessment and biopsy of potentially haemorrhagic lesions and the debulking of large tumours [8-10]. In addition, many physicians are now relearning the technique to facilitate endobronchial laser therapy and stenting procedures [11].

\section{The diagnostic yield of fibreoptic bronchoscopy}

The expected diagnostic yield from FOB depends on the location and distribution of the tumour. Central endobronchial lesions yield the highest diagnostic return $(>90 \%)$, whilst small peripheral lesions often prove more elusive unless more demanding and time-consuming techniques are used. The question of which combination of cytological and histological procedures provides the optimum diagnostic yield has not been conclusively answered but probably depends on the expertise available in any individual centre. The routine techniques include bronchial washings, brushings and biopsies but these may be augmented by the use of transbronchial needle aspiration (TBNA) and bronchoalveolar lavage (BAL) [12].

More than $70 \%$ of lung carcinomas are visible to the FOB and although the yield is dependent on operator experience, a high level of diagnostic accuracy can be achieved by taking between three and five biopsy specimens and a combination of brushing, biopsy and bronchial washes can expect to establish a diagnosis in
$>60 \%$ of cases $[6,7,13,14]$. When the tumour is visible but is intramural rather than endobronchial in distribution, the diagnostic yield falls to $55 \%$ and is reduced further when the tumour lies beyond the bronchoscopist's vision $[6,7,12]$.

The main role of BAL in patients with lung cancer is the diagnosis of opportunistic infections in patients undergoing chemotherapy. However, BAL may have an extended role in the diagnosis of malignancy itself. A high diagnostic yield has been shown in the detection of pulmonary haematological malignancies, primary bronchoalveolar cell carcinoma and metastatic adenocarcinoma of the breast [15-17].

Information on the role of BAL in the diagnosis of primary lung cancer remains sparse.

Examination of BAL from 55 patients with a peripheral lung lesion demonstrated a diagnostic yield of $\sim 30 \%$ with no false-positive results and only one instance of incorrect cell typing. Additionally, in combination with bronchial washing and postbronchoscopy sputum, BAL increased the yield to $56 \%$ [18]. Examination of BAL in 162 patients with malignant lung infiltrates revealed improved sensitivity in cases of bronchoalveolar cell carcinoma (93\%) and lymphangitis carcinomatosa (83\%). $45 \%$ of non-Hodgkin's lymphoma was detected and immunocytochemistry was of value in identification and classification [19].

BAL is safe; bleeding and pneumothorax are uncommon and the fever and transient loss of lung function reported are rarely serious and there is no requirement for fluoroscopy. Furthermore, the diagnostic yield is high in diseases other than cancer, such as pulmonary tuberculosis. Advances in cell and molecular biology may complement the technique of BAL to improve the rate of tumour diagnosis in peripheral lesions (particularly adenocarcinoma) and may also provide a useful tool to explore the molecular mechanisms governing the genesis of lung cancer [20-22].

\section{Visible endobronchial lesions}

Central tumours can present as exophytic mass lesions, with partial or total occlusion of the bronchial lumen, as peribronchial tumours with extrinsic compression of the airway, or with submucosal infiltration of tumour. The changes with peribronchial tumours or with submucosal infiltration are often subtly, the airways should be examined closely for characteristic changes, 
such as erythema, loss of bronchial markings and nodularity of the mucosal surface. Central lesions are usually sampled with a combination of bronchial washes, bronchial brushings and endobronchial biopsies. The yield of endobronchial biopsies is highest for exophytic lesions, with a diagnostic yield of 90\% [23-25]. Three to four biopsies are likely adequate in this situation. Attempts should be made to obtain the biopsies from areas of the lesion that seem viable.

For submucosal lesions, TBNA can be performed by inserting the needle into the submucosal plane at oblique angle, and in patients with peribronchial disease and extrinsic compression, the needle should be passed through the bronchial wall into the lesion $[26,27]$. It is particularly frustrating when apparently adequate biopsy specimens from visible endobronchial disease fail to achieve a diagnosis. Reasons for this include the presence of surface necrosis or the presence of crush artefact (particularly common with samples from small cell carcinoma). In these circumstances, TBNA may improve diagnostic yield $[28,29]$.

Regarding the Tstaging, FOB may allow the operator to determine that the tumour is beyond resection. Pointers to inoperability include: paralysis of a vocal cord; tumour to the level of the right tracheobronchial junction or to within $2 \mathrm{~cm}$ of the left tracheobronchial junction; and definite carinal or tracheal involvement (fig. 1).

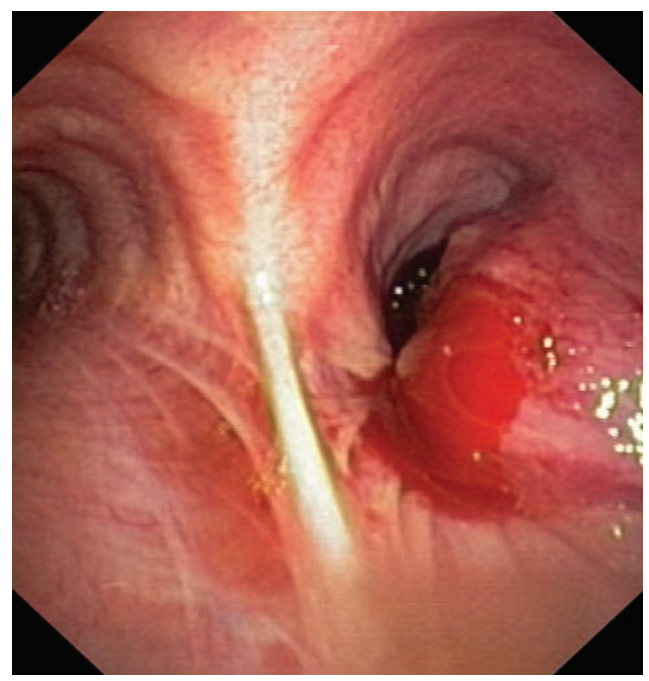

Figure 1

Fibreoptic bronchoscopic image showing a tumour that is inoperable due to location.

\section{Peripheral lung lesions}

Peripheral lesions are usually sampled with a combination of bronchial wash, brushes, transbronchial biopsy and TBNA. The diagnostic yield of bronchoscopy for peripheral lesions depends on a number of factors, including lesion size, the distance of the lesion from the hilum and on the relationship between the lesion and bronchus. The yield of bronchoscopy for lesions $<3 \mathrm{~cm}$ varies from $14-50 \%$ compared with a diagnostic yield of $46-80 \%$ when the lesion is $>3 \mathrm{~cm}$ [30-32]. The presence of a bronchus sign on chest $C T$ predicts a much higher yield of bronchoscopy for peripheral lung lesions. In these cases, fluoroscopic guidance should be used to ensure proper positioning of the diagnostic accessory (fig. 2).

Fluoroscopy increases the diagnostic yield from transbronchial biopsy (TBBX) in focal lung lesions but it is time consuming, requires experience and is not universally available. However, if the disease process is diffuse, such as in lymphangitis carcinomatosa, yields are similar whether fluoroscopy is used or not [33] Indeed, Tbbx may be regarded as the procedure of choice for lymphangitis carcinomatosa. Complications from TBBX include pneumothorax and haemorrhage but these are generally low and rarely serious.

In situations where bronchial biopsies cannot be obtained, examination of bronchial washings may still yield useful information and often provide complementary information $[34,35]$. It is often prudent to perform all types of sampling procedure to maximize the yield [12].

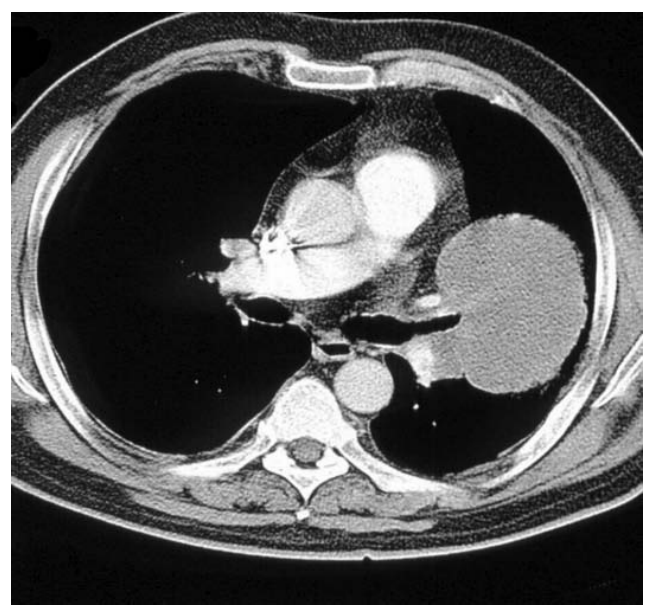

Figure 2

Computed tomography image of a chest showing a bronchus sign. 
Several studies have demonstrated that TBNA may be used to obtain diagnostic tissue from peripheral lesions. Typical results report an increase in the diagnostic yield from percentage figures in the mid-30s up to the high-60s $[12,36-38]$. As with Tbbx, the size of the peripheral lesion appears to be important; although, this is not a feature of all studies. Optimum yields are provided by employing a combination of diagnostic techniques. TBNA may represent an alternative to TBBX when the airway is stenosed or externally compressed to such a degree that it is not possible to pass the TBBX forceps.

The need to workup and manage pulmonary nodules and masses is encountered with increasing frequency in chest medicine. In patients with such nodules, the diagnostic procedure is usually performed as a TBBX under fluoroscopic guidance. The commonly performed procedure, endoscopic transbronchial biopsy, is associated with a low yield in coin lesions $<3 \mathrm{~cm}$ in size or fluoroscopically invisible lesion problems. The yield depends greatly on the size and location of the abnormality $[39,40]$ and generally on the ability to visualise the lesion fluoroscopically. Nodules that are too small to be visualised by conventional fluoroscopy during the procedure pose a particular problem and usually require further, often surgical, biopsy procedures.

If issues of diagnostic yield could be resolved, flexible bronchoscopy would represent a very interesting part in the workup and management of lung lesions. What is needed, therefore, are new methods for navigation and localisation, independent of visualisation by fluoroscopy, but still dependent on the technical skills of the bronchoscopist. Promising new technologies are electromagnetic navigation and endobronchial ultrasound.

\section{Electromagnetic navigation}

The electromagnetic navigation system is a localisation device that assists in placing endobronchial accessories (e.g., forceps, brush and needle) in the desired areas of the lung.

The system uses low-frequency electromagnetic waves, which are emitted from an electromagnetic board placed under the bronchoscopy table mattress. A 1-mm diameter, 8-mm-long sensor probe mounted on the tip of a flexible metal cable constitutes the main assembly of the device (locatable guide). Once the probe is placed within the electromagnetic field, its position in the $X, Y$ and $Z$ planes, as well as its orientation (roll, pitch and yaw movements), are captured by the electromagnetic navigation system. This information is then displayed on a monitor in real time. The locatable guide also has an added feature that allows its distal section to be steered $360^{\circ}$. The fully retractable probe is incorporated into a flexible catheter (serving as an extended working channel), which, once placed in the desired location, creates an easy access for bronchoscopic accessories. The computer software and monitor allow the bronchoscopist to view the reconstructed three-dimensional computer tomography (CT) scans of the object's anatomy in coronal, sagittal and axial views together with superimposed graphic information depicting the position of the sensor probe.

There are still some major limitations to the technique. For planning, a CT scan is necessary with a special protocol (1-mm cuts and tight overlay). For the planning of the procedure, the use of the electromagnetic navigation bronchoscopy (ENB) software is required. The planning can be done even on the system or on a special dedicated laptop before the procedure; the planning needs some time, up to $10 \mathrm{~min}$ in trained colleagues. The whole procedure time is prolonged compared with a traditional diagnostic bronchoscopy with fluoroscopy; but compared with the technique we have at the moment for lesions of this size, CT-guided punctures, the time is equivalent. Last but not least, the locatable guide is single use and costs US $\$ 500-1,000$, depending on the market. The reimbursements are also dependent on the local systems and vary US\$0-1,000. SCHWARz et al. [41] performed a trial to determine the practicality, accuracy and safety of real-time electromagnetic navigation in locating artificially created peripheral lung lesions in a swine model. No adverse effects, such as pneumothorax or internal bleeding, were encountered in any animal in this study. They concluded that real-time electromagnetic positioning technology, coupled with previously acquired $\mathrm{CT}$ scans, is an accurate technology that can augment standard bronchoscopy to assist in reaching peripheral lung lesions and performing biopsies.

Based on the results of that study, BECKER et al. [42] performed a pilot study in humans. They examined the utility of the system in 30 consecutive patients presenting for endoscopic evaluation of lung nodules and masses. The 
lesion size in this population varied 12-106 mm but was specifically not controlled for in this early trial. Evaluation was possible in 29 patients and, in 20 patients, a definitive diagnosis was established, with no complications related to the navigation device.

In an uncontrolled study, again SCHWARZ et al. [43] confirmed that the procedure was safe and added only an average of 15 min to the time of a conventional bronchoscopy. Successful diagnostic biopsies were obtained in $69 \%$ of patients. A follow-up study of 60 patients [44], published in 2006, successfully reached the target lesion in 100\% of cases. Bronchoscopy with electromagnetic navigation diagnosed $80.3 \%$ of the lesions, $74 \%$ of the peripheral lesions and $100 \%$ of the lymph nodes. Of the lesions, $57 \%$ were $<2 \mathrm{~cm}$ in size. Diagnostic yield did not differ significantly based on the size of the lesion. The accuracy of ENB navigation has been proven in animal studies and against fluoroscopically verified reference points in humans $[43,44]$. Nevertheless, all preceding diagnostic studies utilising ENB also used fluoroscopy to guide biopsies. The role of ENB as a standalone technology is still unproven and concerns remain that biopsy instruments may dislodge an accurately positioned extended working channel (EWC) when replacing the sensor probe.

EBERHARDT et al. [45] examined the yield of ENB without fluoroscopy in the diagnosis of peripheral lung lesions and solitary pulmonary nodules. 92 peripheral lung lesions were biopsied in the 89 subjects. The diagnostic yield of ENB was $67 \%$, which was independent of lesion size. The mean navigation error was $9 \pm 6 \mathrm{~mm}$ (range 1-31 mm). When analysed by lobar distribution, there was a trend towards a higher ENB yield in diagnosing lesions in the right middle lobe (88\%). The study concluded that ENB could be used as a standalone bronchoscopic technique without compromising diagnostic yield or increasing pneumothorax risk. This may result in sizable time saving and avoids radiation exposure.

MAKRIS et al. [46] confirmed these results. In 40 patients all target lesions but one were reached and the overall diagnostic yield was $62.5 \%$ (25 out of 40 ). Also, the French group summarised that electromagnetic navigationguided bronchoscopy has the potential to improve the diagnostic yield of transbronchial biopsies without further fluoroscopic guidance and may be useful in early diagnosis of lung cancer, particularly in non-operable patients.

\section{Endobronchial ultrasound}

At the moment, two different systems are available. The linear endobronchial ultrasound (EBUS) bronchoscope, which incorporates the ultrasound transducer at its distal end, utilises a fixed array of transducers aligned in a curvilinear pattern.

Owing to the size of the scope, the system is usable only in the central airways. For the peripheral lung the radial EBUS must be used. The radial EBUS system consists of a mechanical radial miniprobe.

Two types of miniprobe are available, one with a notch at the tip for a water-fillable balloon catheter, one without a notch. Particularly with the notch type, ultrasonography can be performed using the balloon method, that is, the balloon is inflated at the distal end of the probe after the probe has been inserted into the instrument channel.

The balloon method makes easy delineation of ultrasound images possible, even at sites where it is hard to retain defecated water. The limitation is the size: with the balloon sheath, an endoscope $\geqslant 2.8 \mathrm{~mm}$ diameter channel has to be used. The notchless probe is smaller $(1.7 \mathrm{~mm})$ and can also be used in smaller scopes.

The 20-MHz frequency is commonly used, although 12- and 30-MHz probes are also available. For use in the peripheral lung, most commonly the probe is placed through a guide sheath in the working channel of the bronchoscope. After localisation of the lesion (fig. 3), the bronchoscope will be kept in place at the nearest visible subsegmental carina and the miniprobe removed. Through the guide sheath, the forceps

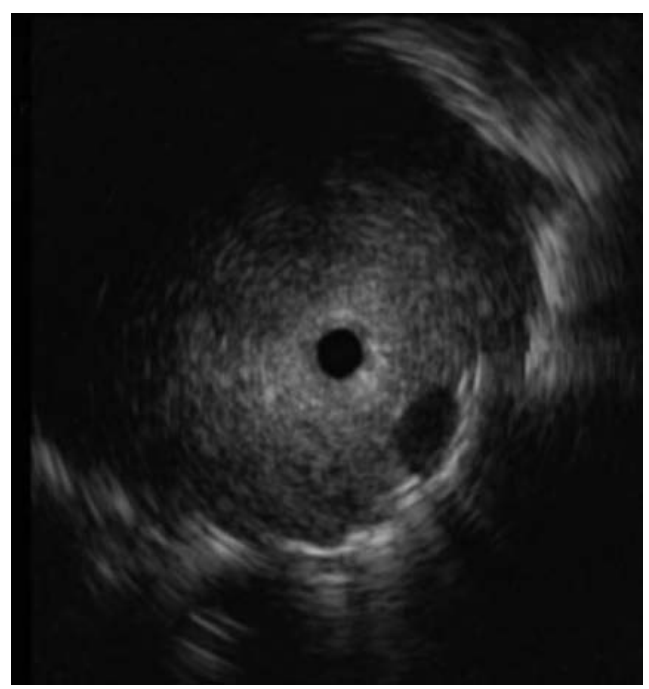

Figure 3

Endobronchial ultrasound showing a lesion. 
are guided to the lesion. By using the guide sheath, EBUS-guided TBBX can be performed without losing the position of the nodule. The first studies were done without the guide sheath; nowadays the guide sheath technique is accept ed as the technique of choice.

The feasibility trial of EBUS-guided TBBX [47] without the use of fluoroscopy showed that EBUS can provide an alternative to fluoroscopy for image guidance in biopsies for peripheral lesions. In the study, a trend towards superior results with EBUS was particularly strong in lesions $<3 \mathrm{~cm}$ in diameter. The same results were shown by SHIRAKAWA et al. [48]. After the feasibility trial, investigators began to examine the use of EBUS as an adjunct for the diagnosis of peripheral lung lesion and solitary pulmonary nodules.

A large prospective study by PAONE et al. [49] compared traditional bronchoscopic transbronchial biopsy with EBUS for peripheral lesions. They found that EBUS-guided bronchoscopy had a sensitivity of 0.83 for lesions $>3 \mathrm{~cm}$ in size and 0.75 for lesions $<3 \mathrm{~cm}$ in size; compared with traditional transbronchial biopsy, EBUS has also shown promise when used for nodules $<3 \mathrm{~cm}$ in size. These types of lesion are often difficult to visualise fluoroscopically for transbronchial biopsies, and bronchoscopy has a low diagnostic yield in such settings.

Most of the published studies have used radiographic fluoroscopy, with radiation exposure for both the patient and medical staff. This result is in line with the study by HERTH et al. [50], including only peripheral pulmonary lesions $<30 \mathrm{~mm}$ and reporting a diagnostic yield of 87\% for EBUS-guided TBBX without the need for radiographic equipment or radiation exposure.

For lesions $<20 \mathrm{~mm}$, the yield of EBUSguided detection and pathologic diagnosis decreased fewer than 30\% yield [51]. By contrast, Japanese groups have reported diagnostic yields of 53 and $72 \%$, respectively, for lesions $<20 \mathrm{~mm}$ using EBUS-guided TBBX with a catheter sheath and under radiographic fluoroscopy $[52,53]$. More recently, one of these Japanese groups have performed EBUS-guided TBBX using virtual bronchoscopic navigation and detected $67 \%$ of lesions $<20 \mathrm{~mm}$ on EBUS, resulting in a diagnostic yield of 44\% [54].

The limitation to these systems is a significant learning curve, and methods of physician training and education still need to be worked out. The technique in the peripheral lung is not as complicated as in the central airways, but the whole procedure must be trained. Also, for EBUS, the reimbursement situation has to be discussed with the local system. However, EBUS lacks a navigation system and requires the operator to manoeuvre the bronchoscope blindly to the lesion with the knowledge of prior radiological investigations, such as CT scans.

Biopsies using ENB have not always resulted in a diagnosis despite accurate navigation in the vast majority of cases to within $10 \mathrm{~mm}$ of the target centre. Respiratory variations causing larger than anticipated navigation errors and dislodgement of the EWC when biopsy instruments were introduced may account for this lowerthan-expected diagnostic yield. ENB lacks a means to directly visualise lesions before biopsy. The role of combining EBUS with ENB to gain the benefits and minimise the limitations of either technique has never been reported. EBERHARDT et al. [55] performed a prospective randomised controlled trial comprising three arms with EBUS only, ENB only and combined EBUS/ENB to test this hypothesis.

Of the 120 patients recruited, 118 had a definitive histological diagnosis and were included in the final analysis. The diagnostic yield of the combined procedure $(88 \%)$ was greater than either endobronchial ultrasound $(69 \%)$ or electromagnetic navigation alone (59\%; $p=0.02)$.

The group concluded that combined endobronchial ultrasound and electromagnetic navigation improves the diagnostic yield of flexible bronchoscopy in peripheral lung lesions without compromising safety.

\section{Mediastinal staging}

\section{Transbronchial needle aspiration}

The first description of sampling mediastinal lymph nodes through the tracheal carina using a rigid bronchoscope was by SCHIEPPATI [56, 57], an Argentinian physician who presented the technique at the Argentine Meeting of Bronchoesophagology in 1949. In 1978, WANG et al. [58] demonstrated that with this technique it was also possible to sample paratracheal nodes. In 1979, Оно et al. [59] introduced a flexible needle that could be utilised through a bronchofibrescope and in 1983, WANG et al. [60] and WANG and TeRRY [61] pointed out the diagnostic possibility of the method in staging of lung cancer and developed new types of needles. Subsequent publications highlighted its utility in 
the diagnosis of endobronchial and peripheral lesions and the ability of TBNA to provide a diagnosis even in the absence of endobronchial disease, in a nonsurgical fashion, confirmed its usefulness to bronchoscopists [62-64].

Operators have reported the use of 21- and 22-gauge cytology needles and 19-gauge histology needles [65]. Further samples are provided by rinsing the needle with a small volume of normal saline and collecting the "flush solution" for analysis. Although TBNA is not widely used, it appears to improve the diagnostic yield when sampling from visible endobronchial, submucosal and peripheral lesions. Additionally the technique may detect mediastinal disease potentially allowing the operator to diagnose and stage a lung tumour in one procedure carried out under local anaesthetic.

TBNA may be used to sample lymph nodes that lie immediately adjacent to the trachea and major bronchi. Care must be taken to perform TBNA prior to inspection of the distal airways and other sampling procedures as contamination with exfoliated malignant cells are a recognised cause of false-positive results. Studies have reported sensitivity rates of $43-83 \%$ and positive predictive values of $89-100 \%$ [66-71]. Use of a 19-gauge needle provides greater sensitivity than a 22-gauge needle but a combination of samples provides the best yields $[65,72]$. Although the positive-predictive value is high (often 100\%) the negative-predictive value is low and does not obviate the requirement for further surgical staging [62-72].

A potential limitation of mediastinal lymph node staging with TBNA is that the operator is blind. The technique may be combined with that of endobronchial ultrasound by the miniprobes $[73,74]$.

The numerous papers on TBNA performed in the last few years confirm the safety of the procedure. No cases of mortality related to TBNA have been described. The rare complications reported are: pneumothorax [75], pneumomediastinum [76], haemomediastinum [77], bacteraemia [78] and pericarditis [79]. None of these complications determined clinical major consequences.

One of the major complications of TBNA is the possible severe damage to the working channel of the scope [64]. This is more frequent with nonretractable needle (that should no longer be available in the market) and can be avoided if the operator takes care in introducing and extracting the needle from the bronchoscope with the tip completely retracted in the sheath.

\section{Endo-oesophageal ultrasound with fine needle aspiration}

Endo-oesophageal ultrasound with fine needle aspiration (EUS-FNA) is a relatively new method, first described in 1991 [80]. Since then, several studies have been published and it has been demonstrated that generally all lesions outlined by EUS may be punctured, and even small lesions down to the size of $5 \mathrm{~mm}$ may be diagnosed [81].

EUS-FNA is performed with the aid of oesophagoscopy and a biopsy needle is passed through the working channel of the endoscope, through the oesophageal wall and guided ultrasonographically toward the lesion of interest in the mediastinum. The procedure is performed under local anaesthetic and conscious sedation. This method gives an excellent overview of mediastinal structures, including a good access to the para-oesophageal space, the aorticopulmonary window, the sub-carinal region and the region around the left atrium (level 4, 5 and 7) [82-84] and then EUS has the advantage of being noninvasive, safe and cost effective [85]. However, an area anterior to the airfilled trachea cannot be visualised.

The procedure can be per formed under i.v. sedation using midazolam or propofol [82]. The echoendoscope is initially introduced up to the level of celiac axis and gradually withdrawn upwards for a detailed mediastinal imaging. Since the ultrasound waves are emitted parallel to the long axis of the endoscope, the entire needle can be visualised approaching a target in the sector-shaped sound field. Pulse-wave Doppler ultrasonography imaging is performed, whenever vascular structures were supposed in the pathway of the needle or adjacent to it, to correct the target line if necessary [84]. The needle is advanced through the wall of the oesophagus and guided into the target lesion. The central stylet is removed, and a special 10-mL syringe attached to the hub of the needle to apply suction as the needle is moved back and forth within the mass. The suction is released slowly and the needle assembly removed out of the biopsy channel. One to two needle passes were made to obtain adequate tissue $[86,87]$.

Visual assessment of mediastinal lymph nodes by EUS gave for various observers sensitivities of $0.54-0.75$, specificities of $0.71-0.98$, positivepredictive values of $0.46-0.77$, and 
negative-predictive values of $0.85-0.93$, in a total of $>1,000$ patients [88]. These studies varied widely with regard to the number of examined mediastinal lymph node levels, visual criteria for malignancy and patient population characteristics. Compared with $C T$, the detection rate of malignant lymph nodes is higher with EUS, with fewer false positive results [89].

EUS can assess mediastinal lymph nodes at most levels, particularly at levels 4 left, 5, 7, 8 and 9 , as well as metastasis in the left adrenal gland. Levels 1, 2, 3 and 4 right are not always assessable, because of interference by air in the larger airways [82, 84]. When enlarged, however, detection is easier [81, 88]. Properties of lymph nodes indicating possible malignancy are a hypoechoic core, sharp edges, round shape and a long axis diameter $>10 \mathrm{~mm}$ [88]. Signs of benignancy are a hyperechoic core (fat), central calcification (old granulomatous disease), illdefined edges, a long and narrow shape and a long axis diameter up to $1 \mathrm{~cm}[89,90]$.

False negative results may have been introduced by the sometimes poor lymph node sampling during EUS-FNA (sampling only the most suspicious nodes). Many outcomes have been supported by clinical instead of surgical follow-up. Despite these drawbacks, the clinical impact of EUS-FNA is illustrated by a change in the management of NSCLC after EUS-FNA in $66 \%$ of the patients or cancellation of 68 and $49 \%$ of the scheduled mediastinoscopies and thoracotomies, respectively.

According to HUNERBEIN et al. [86], EUS-FNA made an unexpected diagnosis in 30\% of the procedures. In two studies with decision-analysis models, EUS-FNA was shown to be less expensive compared with mediastinoscopy for the assessment of the entire mediastinum or for subcarinal lymph nodes only [82, 91, 92].

BARAWI et al. [93] prospectively studied the incidence of complications associated with EUSFNA. In 842 mediastinal EUS-FNA procedures, 1 infection, 2 haemorrhages and 1 inexplicable transient hypotension were reported. EUS-FNA is relatively contraindicated in patients with a Zenker's diverticulum or bleeding tendency [94].

FNA of a cystic mediastinal lesion should be avoided, or when necessary be preceded by prophylactic antibiotics [95].

\section{EBUS-TBNA}

Lymph node staging is also the main indication for use of the new EBUS-TBNA scope. An ultrasound transducer integrated into a bronchoscope with a separate working channel would potentially increase the yield of TBNA by allowing direct visualisation of needle placement within the area of interest. So a special ultrasonic puncture bronchoscope by integrating a convex probe at the tip of the flexible bronchoscope was developed. With this bronchoscope direct TBNA under real-time convex probe endobronchial ultrasonography (EBUS-TBNA bronchoscopy) guidance is now possible.

EBUS-TBNA is performed by direct transducer contact with the wall of the trachea or bronchus. When a lesion is outlined, a 22-gauge full-length steel needle is introduced through the biopsy channel of the endoscope. Power Doppler examination may be performed before the biopsy to avoid unintended puncture of vessels. Under real-time ultrasonic guidance, the needle is placed in the lesion (fig. 4). Suction is applied with a syringe and the needle is moved back and forth inside the lesion [96].

EBUS-TBNA has now been available for more than 5 years. A growing body of research supports its usefulness in airway assessment and procedure guidance, especially since PET is available [97-100].

EBUS-TBNA has access to all of the mediastinal lymph node stations accessible by mediastinoscopy as well as N1 nodes. The largest trial reported the results of the method in 502 patients [101]. 572 lymph nodes were punctured and 535 (94\%) resulted in a diagnosis. Biopsies were taken from all reachable lymph node stations (2l, 2r, 3, 4r, 4l, 7, 10r, 10l, $11 \mathrm{r}$ and 111 . Mean \pm SD diameter of the nodes was $1.6 \pm 0.36 \mathrm{~cm}$ and the range was $0.8-$ $3.2 \mathrm{~cm}$. Sensitivity was $92 \%$, specificity was $100 \%$ and the positive-predictive value was

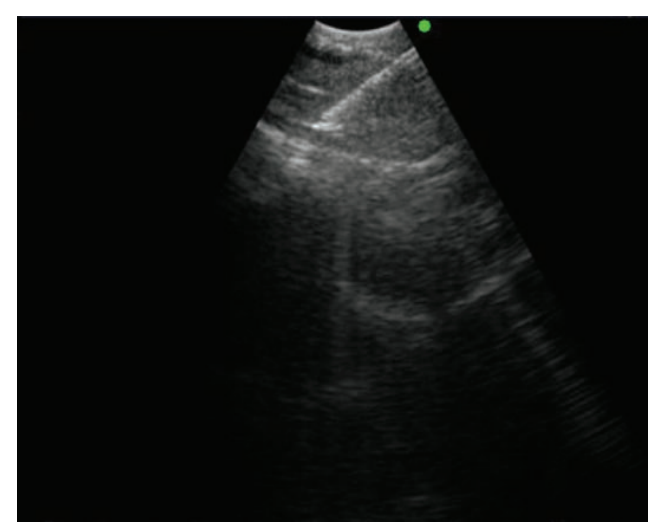

Figure 4

Real-time ultrasonic guidance used to insert a needle into an identified lesion. 
93\%. As in all other trials, no complications occurred.

A Danish-German group [102] additionally examined the accuracy of EBUS-TBNA in sampling nodes $<1 \mathrm{~cm}$ in diameter. Among 100 patients, 119 lymph nodes with a size of 4-10 mm were detected and sampled. Malignancy was detected in 19 patients but missed in two others; all diagnoses were confirmed by surgical findings. The mean diameter of the punctured lymph nodes was $8.1 \mathrm{~mm}$. The sensitivity of EBUS-TBNA for detecting malignancy was $92.3 \%$; the specificity was $100 \%$; and the negative-predictive value was $96.3 \%$. Again, no complications occurred. They summarised that EBUS-TBNA can sample even small mediastinal nodes, therefore avoiding unnecessary surgical exploration in 1 out of 5 patients who have no CT evidence of mediastinal disease. Potentially operable patients with clinically nonmetastatic NSCLC may benefit from presurgical EBUS-TBNA biopsies and staging. A study comparing EBUS-TBNA, CT and PET for lymph node staging of lung cancer showed a high yield for EBUS-TBNA [103]. Altogether, 102 potentially operable patients with proven $(n=96)$ or radiologically suspected $(n=6)$ lung cancer were included in the study. CT, PET and EBUS-TBNA were performed prior to surgery for the evaluation of mediastinal and hilar lymph node metastasis. The sensitivities of CT, PET and EBUS-TBNA for the correct diagnosis of mediastinal and hilar lymph node staging were 76.9, 80.0 and $92.3 \%$, respectively; the specificities were $55.3,70.1$ and $100 \%$, respectively; and the diagnostic accuracies were 60.8, 72.5 and $98.0 \%$, respectively. EBUS-TBNA was proven to have high sensitivity and specificity, compared with $\mathrm{CT}$ or PET, for mediastinal staging in patients with potentially resectable lung cancer.

Restaging of the mediastinum is another area of growing interest for the treatment strategy of lung cancer. In cases of advanced lymph node stage lung cancer, induction chemotherapy prior to surgical resection is an option. Mediastinoscopy is considered the gold standard for staging the mediastinum. However, remediastinoscopy can be technically difficult and is therefore not commonly performed. The ability to perform multiple, repeat biopsies using EBUS-TBNA allows restaging of the mediastinum after the introduction of chemotherapy.

A group of 124 consecutive patients with tissue-proven IIIA-N2 disease who were treated with induction chemotherapy underwent mediastinal restaging by EBUS-TBNA. The sensitivity, specificity, positive predictive value, negative predictive value, and diagnostic accuracy of EBUS-TBNA for mediastinal restaging following induction chemotherapy were 76, 100, 100, 20 and $77 \%$, respectively. EBUS-TBNA is an accurate, minimally invasive test for mediastinal restaging of patients with NSCLC. However, because of the low negative-predictive value, tumour-negative findings should be confirmed by surgical staging [104].

EBUS-TBNA can be also used for the diagnosis of intrapulmonary nodules as well as mediastinal and hilar lymph nodes. The limitation is the reach of EBUS-TBNA, which depends on the size of the bronchus. Usually the EBUSTBNA can be inserted as far as the lobar bronchus. Lung tumours located adjacent to the airway within reach of EBUS-TBNA can be diagnosed with EBUS-TBNA. ToRnouY et al. [105] have reported their experience is this indication. In 60 patients, who have had a nondiagnostic bronchoscopy before, they were able to establish the defintive diagnosis in $77 \%$ without any complication.

Complications related to the procedure are similar to those of conventional TBNA, including bleeding from major vessels, pneumomediastinum, mediastinitis, pneumothorax, bronchospam and laryngospasm. Complications related to EBUS-TBNA have not been observed and to date there are no major complications reported in the literature. Although EBUS has enabled the bronchoscopist to see beyond the airway, one must be aware of the possible complications related to the procedure $[106,107]$.

\section{Rapid on-site evaluation}

Rapid on-site evaluation (ROSE) is comparable with the intra-operative frozen-section examination. The technique requires the cytopathologist and the pathology technician to process and interpret the stained wet film of the aspirate immediately and report the result to the bronchoscopist. For all needle techniques advantages are to resume. Several studies have shown that ROSE reduces the incidence of inadequate specimens, an important cause of nondiagnostic TBNA aspirates [108-111].

DAVENPORT [112] studied the value of ROSE in 73 aspirates and compared the results with 134 specimens processed routinely. The aspirates were obtained from the mediastinal lymph nodes and the peripheral lung nodules. With ROSE, the proportion of aspirates showing malignant cells increased from $31 \%$ to $56 \%$. 
The proportion of the inadequate negative specimens dropped from $56 \%$ to $18 \%$. The negative aspirate with ROSE had a higher negative-predictive value than that of routinely prepared specimens. In a recent prospective study, Dietre et al. [113] evaluated transbronchial needle aspirates with ROSE in 81 of 204 cases. The overall diagnostic yield was $81 \%$ when ROSE was used compared with a $50 \%$ yield when specimens were processed in the usual manner. Multivariate analysis showed that ROSE was an independent predictor of a positive aspirate for malignant cells with an odds ratio of 4.5. The mean number of needle attempts was slightly greater with ROSE. The concordance between the preliminary diagnosis made in the bronchoscopy suite and the final diagnosis was reached after subsequent review of material in the cytopathology laboratory was $87 \%$ indicating that the onsite evaluation of needle aspirate is fairly accurate but not perfect.

Although ROSE seems to improve the diagnostic yield of TBNA, its costeffectiveness remains unclear. Successful use of ROSE requires services of an expert cytopathologist. Many pathologists do not favour ROSE because of the extra time and effort involved. The reimbursement from a third-party payer for these services is highly variable. Presently, the decision to use ROSE should be made on a case-by-case basis.

\section{References}

1. KilIian G. Ueber directe Bronchoscopie. MMW 1898; 27: 844-847.

2. Jackson Ch. The life of Chevalier Jackson. An autobiography. New York, Macmillan, 1938.

3. Ohata M. History and Progress of Bronchology in Japan. JJSB 1998; 20: 539-546.

4. Barlési F, Doddoli C, Greillier L, et al. Bronchoscopy in the diagnosis of lung cancer: an evaluation of current practice. Rev Mal Respir 2006; 23: 17-26.

5. Becker HD, Shirakawa T, Tanaka F, et al. Transbronchial lung biopsy in the immunocompromised patient. Eur Respir Mon 1998; 9: 193-208.

6. Mazzone P, Jain P, Arroliga AC, et al. Bronchoscopy and needle biopsy techniques for diagnosing and staging of lung cancer. Clin Chest Med 2002; 23: 137-158.

7. El-Bayoumi E, Silvestri GA. Bronchoscopy for the diagnosis and staging of lung cancer. Semin Respir Crit Care Med 2008; 29: 261-270.

8. Wahidi MM, Herth FJ, Ernst A. State of the art: interventional pulmonology. Chest 2007; 131: $261-274$.

9. Herth FJF, Ernst A. Innovative bronchoscopic diagnostic techniques: endobronchial ultrasound and electromagnetic navigation. Curr Opin Pulm Med 2005; 11: 278-281.

10. Folch E, Mehta AC. Airway interventions in the tracheobronchial tree. Semin Respir Crit Care Med 2008; 29: 441452.

11. Herth FJF, Eberhardt R. Interventional bronchoscopy. Minvera Pneumol 2004; 43: 189-201.

12. Gasparini S, Ferrety M, Such E, et al. Integration of transbronchial and percutaneous approach in the diagnosis of peripheral pulmonary nodules or masses: experience with 1027 consecutive cases. Chest 1995; 108: $131-137$.

13. Govert JA, Dodd LG, Kussin PS, et al. A prospective comparison of fiberoptic transbronchial needle aspiration and bronchial biopsy for bronchoscopically visible lung carcinoma. Cancer 1999; 87: 129-134.

14. Govert JA, Kopita JM, Matehar D, et al. Cost-effectiveness of collecting cytologic specimens during fiberoptic bronchoscopy for endoscopically visible lung tumors. Chest 1996; 109: 451-456.

15. De Gracia J, Bravo C, Miravitalles M, et al. Diagnostic value of bronchoalveolar lavage in peripheral lung cancer. Am Rev Respir Dis 1993; 147: 649-652.

16. Fabin E, Nagy M, Meszaros G. Experiences with bronchial brushing method. Acta Cytol 1975; 19: 320-321.

17. Fedullo AJ, Ettensohn DB. Bronchoalveolar lavage in the lymphangitic spread of adenocarcinoma to the lung. Chest 1985; 87: 129-131.

18. Semenzato G, Spatafora M, Feruglio C, et al. Bronchoalveolar lavage and the immunology of lung cancer. Lung 1990; 168: 1681-1689.

19. Rennard SI. Bronchoalveolar lavage in the diagnosis of cancer. Lung 1990; 168: 1035-1040.

20. Garg S, Handa U, Mohan H, et al. Comparative analysis of various cytohistological techniques in diagnosis of lung diseases. Diagn Cytopathol 2007; 35: 26-31.

21. Emad A, Emad V. The value of BAL fluid LDH level in differentiating benign from malignant solitary pulmonary nodules. J Cancer Res Clin Oncol 2008; 134: 489-493.

22. Azoulay E, Schlemmer B. Diagnostic strategy in cancer patients with acute respiratory failure. Intensive Care Med 2006; 32: 808-822.

23. Wilson RW, Frazier AA. Pathological-radiological correlations: pathological and radiological correlation of endobronchial neoplasms: part II, malignant tumors. Ann Diagn Pathol 1998; 2: 31-34.

24. Simoff MJ. Endobronchial management of advanced lung cancer. Cancer Control 2001; 8: 337-343.

25. Schreiber G, McCrory DC. Performance characteristics of different modalities for diagnosis of suspected lung cancer: summary of published evidence. Chest 2003; 123: 115S-128S.

26. Dasgupta A, Jain $P$, Minai $0 A$, et al. Utility of transbronchial needle aspiration in the diagnosis of endobronchiallesions. Chest 1999; 115: 1237-1241.

27. Dasgupta A, Mehta AC. Transbronchial needle aspiration: An underused diagnostic technique. Clin Chest Med 1999; 20: $39-51$. 
28. Gasparini S. Evolving role of interventional pulmonology in the interdisciplinary approachto the staging and management of lung cancer: bronchoscopic mediastinal staging of lung cancer. Clin Lung Cancer 2006; 8: 110115.

29. Horsley JR, Miller RE, Amy RWM, et al. Bronchial submucosal needle aspiration performed through the fiberoptic bronehoscope. Acta Cytol 1984; 28: 211-217.

30. Gasparini S. Bronchoscopic biopsy techniques in the diagnosis and staging of lung cancer. Monaldi Arch Chest Dis 1997; 4: 392-398.

31. Hanson RR, Zavala DC, Rhodes ML, et al. Transbronchial biopsy via flexible fiberoptic bronchoscope: Result in 164 patients. Am Rev Respir Dis 1976; 114: 67-72.

32. Govert JA, Dodd LG, Kussin PS, et al. A prospective comparison of fiberoptic transbronchial needle aspiration and bronchial biopsy for bronehoscopically visible lung carcinoma. Cancer 1999; 87: 129-134.

33. Pisani RJ, Wright AJ. Clinical utility of bronchoalveolar lavage in immunocompromised hosts. Mayo Clin Proc 1992; 67: 221-227.

34. Cortese DA, McDougaIl JC. Biopsy and brushing of peripherallung cancers with fluoroscopic guidance. Chest 1979; 75: 141-145.

35. Schreiber G, McCrory DC. Performance characteristics of different modalities for diagnosis of suspected lung cancer: summary of published evidence. Chest 2003; 123: 115S-128S.

36. Yung RC. Tissue diagnosis of suspected lung cancer: selecting between bronchoscopy, transthoracic needle aspiration, and resectional biopsy. Respir Care Clin N Am 2003; 9: 51-76.

37. Liam CK, Pang YK, Poosparajah S. Diagnostic yield of flexible bronchoscopic procedures in lung cancer patients according to tumour location. Singapore Med J 2007; 48: 625-631.

38. Ellis JH Jr. Transbronchial biopsy via the fiberoptic bronchoscope: Experience with 107 consecutive cases and comparison with bronchial brushing. Chest 1975; 68: 524-532.

39. Schreiber G, McCrory DC. Performance characteristics of different modalities for diagnosis of suspected lung cancer: summary of published evidence. Chest 2003; 123: 115-128.

40. Baaklini WA, Reinoso MA, Gorin AB, et al. Diagnostic yield of fiberoptic bronchoscopy in evaluating solitary pulmonary nodules. Chest 2000; 117: 1049-1054.

41. Schwarz Y, Mehta AC, Ernst A, et al. Electromagnetic navigation during flexible bronchoscopy. Respiration 2003; 70: 516-522.

42. Becker HD, Herth F, Ernst A, et al. Bronchoscopic biopsy of peripheral lung lesions under electromagnetic guidance. J Bronchol 2005; 12: 9-13.

43. Schwarz Y, Greif J, Becker HD, et al. Real-time electromagnetic navigation bronchoscopy to peripheral lung lesions using overlaid CT images: the first human study. Chest 2006; 129: 988-994.

44. Gildea TR, Mazzone PJ, Karnak D, et al. Electromagnetic navigation diagnostic bronchoscopy: a prospective study. Am J Respir Crit Care Med 2006; 174: 982-989.

45. Eberhardt R, Anantham D, Herth FJF, et al. Electromagnetic navigation diagnostic bronchoscopy in peripheral lung lesions. Chest 2007; 131: 1800-1805.

46. Makris D, Scherpereel A, Leroy S, et al. Electromagnetic navigation diagnostic bronchoscopy for small peripheral lung lesions. Eur Respir J 2007; 29: 1187-1192.

47. Herth F, Ernst A, Becker H. Endobronchial ultrasound-guided transbronchial lung biopsy in solitary pulmonary nodules and peripheral lesions. Eur Respir J 2002; 20: 972-974.

48. Shirakawa T, Imamura F, Hamamoto J, et al. Usefulness of endobronchial ultrasonography for transbronchial lung biopsies of peripheral lung lesions. Respiration 2004; 71: 260-268.

49. Paone $G$, Nicastri $E$, Lucantoni $G$, et al. Endobronchial ultrasound-driven biopsy in the diagnosis of peripheral lung lesions. Chest 2005; 128: 3551-3557.

50. Herth FJ, Becker HD, Ernst A, et al. Endobronchial ultrasound-guided transbronchial lung biopsy in fluoroscopically invisible solitary pulmonary nodules: a prospective trial. Chest 2006; 129: 147-150.

51. Dooms CA, Verbeken EK, Becker HD, et al. Endobronchial ultrasonography in bronchoscopic occult pulmonary lesions. J Thorac Oncol 2007; 2: 121-124.

52. Kurimoto N, Miyazawa T, Okimasa $\mathrm{S}$, et al. Endobronchial ultrasonography using a guide sheath increases the ability to diagnose peripheral pulmonary lesions endoscopically. Chest 2004; 126: 959-965.

53. Kikuchi E, Yamazaki K, Sukoh N, et al. Endobronchial ultrasonography with guide sheath for peripheral pulmonary lesions. Eur Respir J 2004; 24: 533-537.

54. Asahina H, Yamazaki K, Onodera Y, et al. Transbronchial biopsy using endobronchial ultrasonography with a guide sheath and virtual bronchoscopic navigation. Chest 2005; 128: 1761-1765.

55. Eberhardt R, Anantham D, Ernst A, et al. Multimodality bronchoscopic diagnosis of peripheral lung lesions: a randomized controlled trial. Am J Respir Crit Care Med 2007; 176: 36-41.

56. Schieppati E. La puncion mediastinal a traves del espolon traqueal [Mediastinal puncture through the tracheal spur]. Rev As Med Argent 1949; 663: 497-499.

57. Schieppati E. Mediastinal lymph nodes puncture through the tracheal carina. Surg Gynecol Obstet 1958; 107: $243-$ 246.

58. Wang KP, Terry PB, Marsh B. Bronchoscopic needIe aspiration biopsy of paratracheal tumors. Am Rev Respir Dis 1978; 118: 17-21.

59. Oho K, Kato H, Ogawa I, et al. A new needle for transfiberoptic bronchoscope use. Chest 1979; 76: 492.

60. Wang KP, Marsh BR, Summer WR, et al. Transbronchial needle aspiration for diagnosis of lung cancer. Chest 1981. 80: 48-50.

61. Wang KP, Terry PB. Transbronchial needle aspiration in the diagnosis and staging of bronchogenic carcinoma. $\mathrm{Am}$ Rev Respir Dis 1983; 127: 344-347.

62. Wang KP, Britt EJ, Haponik EF, et al. Rigid transbronchial needle aspiration biopsy for histological specimens. Ann Otol Rhinol LaryngoI 1985; 94: 382-385.

63. Schenk DA, Bower JH, Bryan CL, et al. Transbronchial needle aspiration staging of bronchogenic carcinoma. Am Rev Respir Dis 1986; 134: 146-148.

64. Dasgupta A, Mehta AC, Wang KP. Transbronchial needle aspiration. Semin Respir Crit Care Med 1997; 18: 571-581.

65. Schenk DA, Chambers SL, et al. Comparison of the Wang 19-gauge and 22-gauge needles in the mediastinal staging of lung cancer. Am Rev Respir Dis 1993; 147: 1251-1258. 
66. Salazar AM, Westcott JL. The role of transthoracic needle biopsy for the diagnosis and staging of lung cancer. Clin Chest Med 1993; 14: 99-110.

67. Jain P, Arroliga A, Mehta AC. Cost-effectiveness of transbronchial needle aspiration in the staging of lung cancer. Chest 1996; 110: 24s.

68. Wang KP, Haponik EF, Gupta PK, et al. Flexible transbronchial needle aspiration: Technical considerations. Ann Otol Rhinol LaryngoI 1984; 93: 233-236.

69. Shure D, Fedullo PF. The role of transcarinal needle aspiration in the staging of bronchogenic carcinoma. Chest 1984; 86: 693-696.

70. Utz JP, Ashok MP, Edell ES. The role of transcarinal needle aspiration in the staging of bronchogenic carcinoma. Chest 1993; 104: 1012-1016.

71. Chin R Jr, McCain TW, Lucia MA, et al. Transbronchial needle aspiration in diagnosing and staging lung cancer. How many aspirates are needed? Am J Respir Crit Care Med 2002; 166: 377-381.

72. Gasparini S, Zuccatosta L, De Nictolis M. Transbronchial needle aspiration ofmediastinal lesions. Monaldi Arch Chest Dis 2000; 1: 29-32.

73. Herth FJ, Becker HD, Ernst A. Ultrasound-guided transbronchial needle aspiration: an experience in 242 patients. Chest 2003; 123: 604-607.

74. Herth F, Becker HD, Ernst A. Conventional versus endobronchial ultrasound-guided transbronchial needle aspiration: a randomized trial. Chest 2004; 125: 322-325.

75. Wang KP, Brower R, Haponik EF, et al. Flexible transbronchial needle aspiration for staging of bronchogenic carcinoma. Chest 1983; 84: 571-576.

76. Harrow EM, Abi-Saleh W, Blum J, et al. The utility of transbronchial needle aspiration in the staging of bronchogenic carcinoma. Am J Respir Crit Care Med 2000; 161: 601-607.

77. Talebian M, Recanatini A, Zuccatosta L, et al. Hemomediastinum as a consequence of transbronchial needle aspiration. J Bronchol 2004; 11: 178-180.

78. Witte MC, Opal SM, et al. Incidence of fever and bacteraemia following transbronchial needle aspiration. Chest 1986; 89: 85-87.

79. Sterling BE. Complication with a transbronchial histology needle. Chest 1990; 98: 783-784.

80. Schuder G, Isringhaus H, Kubale B, et al. Endoscopic ultrasonography of the mediastinum in the diagnosis of bronchial carcinoma. Thorac Cardiovasc Surg 1991; 39: 299-303.

81. Vilmann P. Endoscopic ultrasonography-guided fine-needle aspiration biopsy of lymph nodes. Gastrointest Endosc 1996; 43: S24-S29.

82. Vilmann P. Endoscopic ultrasound-guided fine-needle biopsy in Europe. Endoscopy 1998; 30: 161-162.

83. Wiersema MJ, Vilmann P, Giovannini M, et al. Endosonography-guided fine-needle aspiration biopsy: diagnostic accuracy and complication assessment. Gastroenterol 1997; 112: 1087-1095.

84. Vilmann P, Hancke S, Henriksen FW, et al. Endosonographically-guided fine needle aspiration biopsy of malignant lesions in the upper gastrointestinal tract. Endoscopy 1993; 25: 523-527.

85. Aabakken L, Silvestri GA, Hawes RH, et al. Cost-efficacy of endoscopic ultrasonography with fine-needle aspiration vs. mediastinotomy in patients with lung cancer and suspected mediastinal adenopathyt. Endoscopy 1999; 31: 707-711.

86. Hunerbein M, Ghadimi BM, Haensch W, et al. Transesophageal biopsy of mediastinal and pulmonary tumors by means of endoscopic ultrasound guidance. J Thorac Cardiovasc Surg 1998; 116: 554-559.

87. Claussen M, Annema JT, Welker L, et al. [Endoscopic ultrasound-guided fine needle aspiration in pulmonary medicine.]. Pneumologie 2004; 58: 435-442.

88. Micames CG, McCrory DC, Pavey DA, et al. Endoscopic ultrasound guided fine-needle aspiration for non-small cell lung cancer staging: A systematic review and metaanalysis. Chest 2007; 131: 539-548.

89. Fritscher-Ravens A, Sriram PV, Bobrowski C, et al. Mediastinal lymphadenopathy in patients with or without previous malignancy: EUS-FNA-based differential cytodiagnosis in 153 patients. Am J Gastroenterol 2000; 95: 2278-2284.

90. Chang KJ, Erickson RA, Nguyen P. Endoscopic ultrasound (EUS) and EUS-guided fine needle aspiration of the left adrenal gland. Gastrointest Endosc 1996; 44: 568-572.

91. Annema JT, Hoekstra OS, Smit EF, et al. Towards a minimally invasive staging strategy in NSCLC: analysis of PET positive mediastinal lesions by EUS-FNA. Lung Cancer 2004; 44: 53-60.

92. Hawes RH, Gress FG, Kesler KA, et al. Endoscopic ultrasound versus computed comography in the evaluation of the mediastinum in patients with non-small-cell lung cancer. Endoscopy 1994; 26: 784-787.

93. Barawi M, Gottlieb K, Cunha B, et al. A prospective evaluation of the incidence of bacteremia associated with EUSguided fine-needle aspiration. Gastrointest Endosc 2001; 53: 189-192.

94. Rabe KF, Welker L, Magnussen H. Endoscopic ultrasonography (EUS) of the mediastinum: safety, specificity, and results of cytology. Eur Respir J 1998; 12: Suppl. 28, 133s.

95. Annema JT, Veselic M, Versteegh MI, et al. Mediastinitis caused by EUS-FNA of a bronchogenic cyst. Endoscopy 2003; 35: 791-793.

96. Herth FJF, Krasnik M, Yasufuku K, et al. Endobronchial ultrasound guided transbronchial needle aspiration: how I do it. J Bronchol 2006; 13: 84-91.

97. Krasnik M, Vilmann P, Larsen SS, et al. Preliminary experience with a new method of endoscopic transbronchial real time ultrasound guided biopsy for diagnosis of mediastinal and hilar lesions. Thorax 2003; 58: 1083-1086.

98. Yasufuku K, Chhajed PN, Sekine Y, et al. Endobronchial ultrasound using a new convex probe: a preliminary study on surgically resected specimens. Oncol Rep 2004; 11: 293-296.

99. Yasufuku K, Chiyo M, Sekine Y, et al. Realtime endobronchial ultrasound-guided transbronchial needle aspiration of mediastinal and hilar lymph nodes. Chest 2004; 126: 122-128.

100. Rintoul RC, Skwarski KM, Murchison JT, et al. Endobronchial and endoscopic ultrasound-guided real-time fineneedle aspiration for mediastinal staging. Eur Respir J 2005; 25: 416-421.

101. Herth FJ, Eberhardt R, Vilmann P, et al. Real-time endobronchial ultrasound guided transbronchial needle aspiration for sampling mediastinal lymph nodes. Thorax 2006; 61: 795-798.

102. Herth FJ, Ernst A, Eberhardt R, et al. Endobronchial ultrasound-guided transbronchial needle aspiration of lymph nodes in the radiologically normal mediastinum. Eur Respir J 2006; 28: 910-914. 
103. Yasufuku K, Nakajima T, Motoori K, et al. Comparison of endobronchial ultrasound, positron emission tomography, and computed tomography for lymph node staging of lung cancer. Chest 2006; 130: 710-718.

104. Herth FJ, Annema JT, Eberhardt R, et al. Endobronchial ultrasound with transbronchial needle aspiration for restaging the mediastinum in lung cancer. $J$ Clin Oncol 2008; 26: 3346-3350.

105. Tournoy KG, Rintoul RC, van Meerbeeck JP, et al. EBUS-TBNA for the diagnosis of central parenchymal lung lesions not visible at routine bronchoscopy. Lung Cancer 2009; 63: 45-49.

106. Trisolini R, Cancellieri A, Tinelli C, et al. Rapid on-site evaluation of transbronchial aspirates in the diagnosis of hilar and mediastinal adenopathy: a randomized trial. Chest 2011; 139: 395-401.

107. Baram D, Garcia RB, Richman PS. Impact of rapid on-site cytologic evaluation during transbronchial needle aspiration. Chest 2005; 128: 869-875.

108. Hsu LH, Liu CC, Ko JS. Education and experience improve the performance of transbronchial needle aspiration: a learning curve at a cancer center. Chest 2004; 125: 532-540.

109. Khoo KL, Ho KY, Nilsson B, et al. EUS-guided FNA immediately after unrevealing transbronchial needle aspiration in the evaluation of mediastinal lymphadenopathy: a prospective study. Gastrointest Endosc 2006; 63: 215-220.

110. Boyan W. On-site cytopathologic analysis of bronchoscopic needle aspiration: con; on-site analysis in not indicated. J Bronchol 2003; 10: 152-154.

111. Nabil C, Smojver-Jezek S. The value of transbronchial needle aspiration combined with rapid on-site evaluation. Acta Med Croatica 2008; 62: 431-434.

112. Davenport RD. Rapid on-site evaluation of transbronchial aspirates. Chest 1990; 98: 59-61.

113. Diette GB, White P Jr, Terry P, et al. Utility of on-site cytopathology assessment for bronchoscopic evaluation of lung masses and adenopathy. Chest 2000; 117: 1186-1190. 